\title{
Building knowledge with theory: Unpacking complexity in doctoral writing
}

\author{
Kirstin Wilmot \\ LCT Centre for Knowledge-Building, University of Sydney, Sydney, Australia ${ }^{1}$ \\ Centre for Higher Education Research, Teaching and Learning (CHERTL), Rhodes University \\ Corresponding author: kirstin.wilmot@cantab.net
}

(Submitted: 20 April 2020; Accepted: 4 August 2020)

\begin{abstract}
The use of theory to analyse and interpret empirical data is a valued practice in much social science doctoral research. A crucial aspect of this practice involves generating sophisticated theoretical understandings and critiques of phenomena in our social world. Despite the importance of theory, however, few concrete explanations of how to 'theorise' exist in literature. This paper addresses this gap by demonstrating how a set of conceptual tools can be used to unpack what the craft of theorising looks like in explicit terms, and to reveal how this ability develops over time during the drafting process of dissertation writing. It does this by drawing on select texts from a successful doctoral dissertation, as well as an earlier draft version. In doing so, the paper provides an in-depth explanation of an essential process of doctoral research that is inherently known by many supervisors, yet seldom unpacked in explicit terms.
\end{abstract}

Keywords: doctoral writing, Legitimation Code Theory, qualitative data analysis, theorising, Semantics, social sciences

\section{Introduction}

The number of candidates pursuing doctoral studies has grown internationally in the last two decades, partly due to the massification of higher education globally which has had knock-on effects for postgraduate studies (Denicolo, 2016). The demand for this elite level of higher education is sought for a variety of reasons, including for example academic advancement and perhaps increasingly, employment opportunities. One of the challenges created by this burgeoning number of doctoral candidates, however, is supervision capacity. Supervisors are increasingly being expected to supervise more students in shorter time frames, and often outside

\footnotetext{
${ }^{1}$ The author is now based at the Centre for Higher Education Research, Teaching and Learning, Rhodes University, Makhanda, South Africa
}

This publication is covered by a Creative Commons Attribution 4.0 International license. For further information please see: http://creativecommons.org/licenses/by/4.0/. 
of their area of expertise (Mouton, 2016). The form dissertations take has also diversified (e.g. monograph, thesis by publication, creative dissertations etc.), as well as the substance of doctoral research, with multiple and novel research designs, methodologies and theories now being enacted. Despite these changes, the importance of being able to work at a conceptual or theoretical level - seen in the inclusion of the word philosophy in the name of the degree, Doctor of Philosophy - is a widely accepted requirement of most PhDs, typically seen as a necessary aspect for generating new knowledge (Lovitts, 2007). The value of using theory for abstracting concrete findings from the confines of a single research site to the wider field and for generating more complex understandings of data has been shown in research (see, for example Wilmot, 2019). However, in a changing higher education context that is producing more PhDs than ever before, with greater demands being made on supervisors, what 'philosophising' looks like in practice and what constitutes 'doctoral level philosophising', is arguably as opaque as other defining features of a PhD, such as 'a contribution to knowledge' (Denicolo 2016: 27; Lovitts, 2007). As such, there is a need to understand these requirements better. One way to address the conceptual or theoretical requirements of the $\mathrm{PhD}$ is to unpack, in explicit terms, how theory can be used to develop sophisticated conceptual accounts of objects of study. Such insight could support supervisors' understanding of how social theory can be enacted in the writing of the dissertation, which in turn, may enhance their supervision practices.

The use of social theory in social science doctoral research is, for the most part, a taken for granted aspect of the doctorate. While the kind of social theories differ vastly, as well as the particular use of theory, it is highly likely that some form of theory will be drawn on in some way. Although commonplace, mastering theory and theorising is not an easy practice - for both the candidate who is learning and the supervisor who is guiding (Holbrook, et al., 2015; Kiley and Wisker, 2009). Scholars have conceded that moving from theory to data and back again - a necessary process involved in theoretical work - is complex (Clegg, 2012). It is also a process that develops gradually over time, often within the private confines of the supervisory relationship, with only the final product being revealed to the field once the practice has been mastered. As such, we, as supervisors and/or academic literacies practitioners, rarely get explicit insight into the process of learning how to theorise.

A common challenge experienced in many contexts is that theory is often 'tagged on' to commonsense interpretations of empirical phenomena, or that theory often slips as the dissertation progresses or indeed drops out entirely by the time the candidate reaches the data analysis component of the dissertation. Trowler (2016: 20) refers to this as 'eminence-based theorising', which he describes as when doctoral candidates 'begin with a panoply of famous men (and sometimes women) rolled out, held up for admiration and then put back into the cupboard'. In effect, theory is used superficially for the sake of theory, and as a consequence, the candidate loses the explanatory power it can provide. This often results in decontextualized thematic or interpretivist content analysis that produces contextually embedded knowledge that is often limited in terms of pushing and critiquing the boundaries of disciplinary knowledge (Jackson and Mazzei, 2012). 
Despite the importance of theory being widely accepted in doctoral studies, few studies exist which unpack the practicalities of working with theory. Notable exceptions exist, for example, Jackson and Mazzei (2012) demonstrate the value of theory by analysing the same set of data using theoretical perspectives offered by six different poststructuralist philosophers. Through this demonstration, the authors argue that data interpretation and analysis by mechanistic means (e.g. thematic coding alone) 'preclude dense and multi-layered treatment of data', and often 'reduce[s] complicated and conflicting voices and data to thematic 'chunks' that can be interpreted free of context and circumstance' (Jackson and Mazzei, 2012: vii-viii). Trowler (2016) also offers an insightful guide to working with theory in doctoral research, usefully outlining common 'sins' in deploying theory so that candidates can get a sense of what not to do.

This paper contributes to these authors' efforts by providing an account of how theoretical engagement develops in the drafting process of the dissertation using a novel conceptual tool from Legitimation Code Theory (LCT) (Maton, 2014). This tool can make explicit what escapes many candidates (and at times, supervisors) when it comes to enacting theory in their dissertation, and why such challenges occur. The paper draws on a particular set of texts taken from a successfully graduated PhD candidate who gave a research seminar as part of the 2015 Legitimation Code Theory Sydney Roundtable series on how the theoretical development of her work occurred over time - an aspect that is commonly known among supervisors but is one that is seldom discussed in more formal contexts such as seminars or publications, or analysed in great detail in research.

\section{Contextualising the data}

In the LCT Roundtable seminar, the candidate whose work is analysed in this paper described her progressive understanding and use of theory in her research as a 'cooking process' - one which moved from a stage of inductive coding to a stage involving movement between inductive and deductive coding, and finally, a third stage involving deductive coding (Glenn, 2015). She also described how her writing became increasingly abstract and condensed with meaning as this 'cooking' process unfolded. Crucially, however, the candidate spoke openly about the fact that this process was neither neat nor straightforward; rather, it was messy, at times confusing and involved multiple iterations and movements back and forward between stages. The process she described is not uncommon in doctoral research - many would argue it is, in fact, the norm.

In order to gain a better understanding of the process the candidate went through, I decided to see if a particular conceptual tool, which is deemed capable of revealing knowledgebuilding strategies, would be able to make the process of 'cooking' more explicit. To this end, I enacted the clausing tool (Maton and Doran, 2017b) on a draft version of a chapter from the candidate's $\mathrm{PhD}$ and compared this to an analysis of the final version of the same chapter. The clausing tool, developed to examine knowledge practices in English discourse, is unpacked in detail below. The aim of using the tool was to generate practical insights to a process that is commonly experienced, but which is difficult to define in concrete terms. 


\section{Building complexity in writing: Theoretical tools and methodological approach}

One of the outcomes of applying theory to data is the ability to build more complex meanings. This involves moving from simple stances (for example, 'I enjoyed the Tuesday reading group where I was able to learn from more experienced peers') to complex ideas (for example, 'Communities of practice are valued by postgraduate students'), often achieved by condensing multiple ideas within one stance. Understanding these meaning-making processes in doctoral writing are commonly analysed and understood through linguistic approaches, with genre-based approaches being the most prevalent (see, for example Swales, 1998; Paltridge, 2002; Starfield and Ravelli, 2006). Recently, however, scholars working in the field of doctoral writing have started to look at how knowledge gets constructed in and through language using a theory of knowledge, rather than one of language. For instance, Ravelli, et al. (2014) look at doctoral dissertations in the creative and performing arts using the dimension of 'Specialization' from LCT - a theory that is capable of revealing strategies used to build knowledge over time. Other, more recent research uses LCT to develop a set of tools for understanding how students move between their raw data to interpretations of that data using theory and how they link these understandings out to existing knowledge in the broader field (Wilmot, 2019).

Maton and Doran $(2017 a, b)$ provide two tools which analyse English discourse in terms of how knowledge is simplified or condensed over time, revealing the cumulative process of knowledge-building. This paper enacts one of these tools - the clausing tool (Maton and Doran, 2017b) - to better understand how the candidate gradually built increasingly complex understandings of her empirical data. The clausing tool essentially identifies and unpacks a number of strategies that are used to build complexity - known in LCT as 'semantic density' over time. Simply put, semantic density refers to how many meanings are 'packed in' to terms (e.g. 'the reading group' versus 'the Bourdieu reading group') - i.e. how complex meanings are or become. In this sense, the clausing tool focuses less on complexity as a fixed characteristic or feature, and rather focuses on how that complexity is developed over time (throughout a text, in a classroom etc.). In other words, it focuses on the process of condensation.

The clausing tool works by showing how meanings get condensed when words are combined into short passages of text - i.e. it reveals the amount and type of new relations established among meanings. This paper only considers 'epistemic' meanings, which are 'formal definitions and empirical descriptions'; it does not consider 'axiological' meanings which relate to affective, aesthetic, ethical, political or moral stances (see Maton and Doran (2017a: 50) for more). Stronger epistemic condensation (written in shorthand as ' $E C+$ ') means more meaning is being related to other meanings; weaker epistemic condensation (EC-) refers to instances where less meaning is being connected up $^{2}$. Put another way, the strength of condensation indicates how much knowledge is being built in one go - stronger condensation (EC+) indicating more

\footnotetext{
${ }^{2}$ Important to emphasise is that the (-) symbol here is not intended to indicate a loss of meaning. Rather, it signifies the fact that relatively few additional meanings are being added at a specific point in time.
} 
knowledge-building, weaker condensation indicating less knowledge-building.

The clausing tool used in this paper is presented in Table 1. This tool enables a dialogue between data and theory by creating a practical bridge between empirical data - in this case a doctoral dissertation - and the theory (Maton and Doran, 2017b). Such a tool is important as theoretical concepts in LCT often look very different when applied to different phenomena: what is complex in images is not the same as what is complex in language or dance or sport. The tool enables the theory to be clearly related to the specific object of study, while also allowing the object of study to speak back to the theory.

As outlined in Table 1, four different clausing strategies are distinguished in this study: taxonomizing, coordinating, characterizing and establishing (see Maton and Doran (2017b) for a more detailed account of the development of the tool). Each strategy is defined and explained using examples in the table. Furthermore, each strategy's relative strength of condensation (i.e. how much or little they 'pack in' meanings) is represented using a plus (+) and minus (-) symbol, with $(++)$ and $(--)$ indicating the strongest and weakest condensation respectively. This coding tool was used to identify and analyse strategies in doctoral writing using two texts: a draft text taken from an early analysis chapter of a PhD thesis, and a final version taken from the successfully examined dissertation.

Table 1. Clausing tool (adapted from Maton and Doran, 2017b)

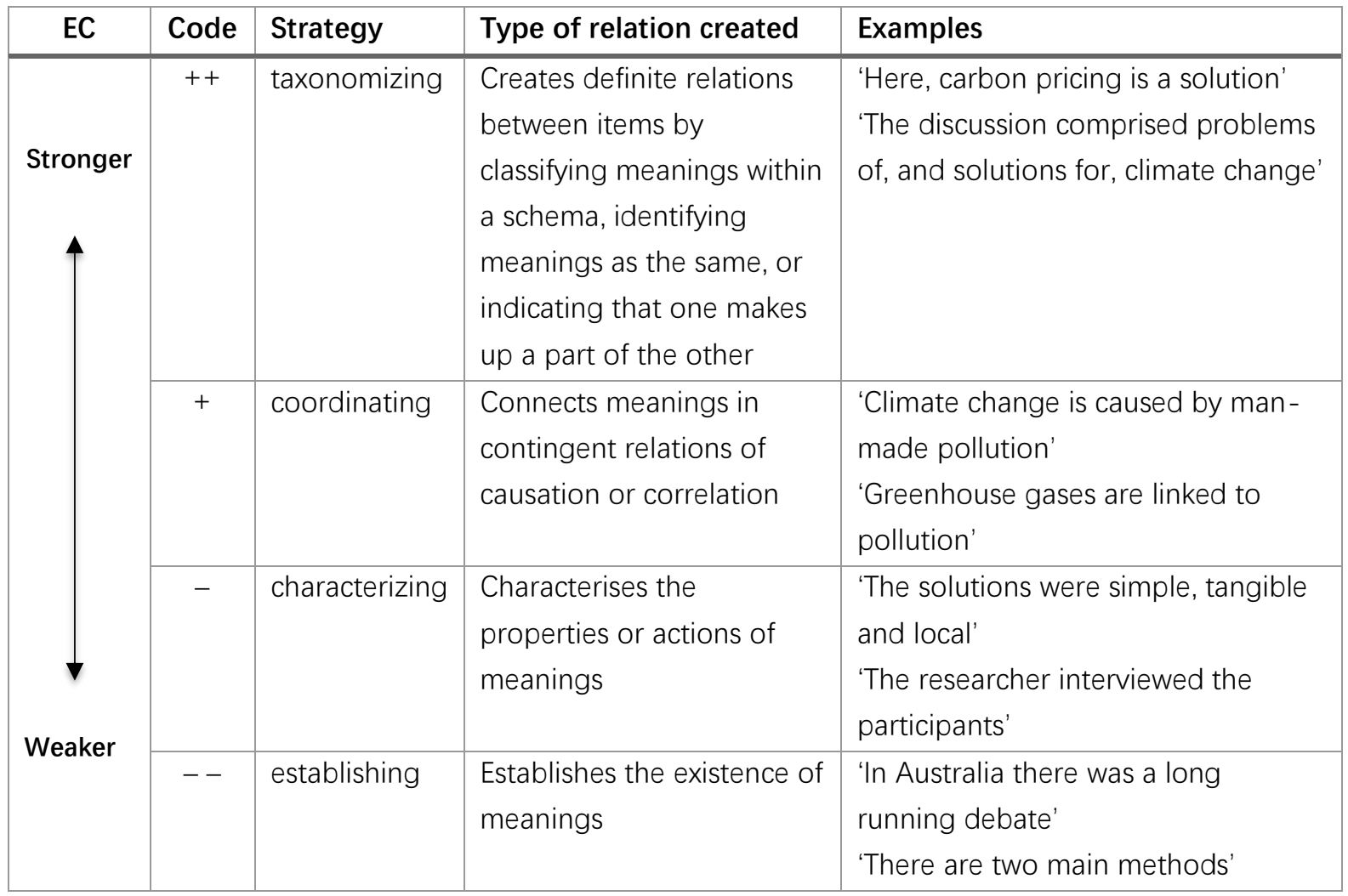


In practical terms, the clausing tool shows relations between two terms, concepts, word groups or meanings of some sort. These are typically connected through a verb, which sets up the particular kind of clausing relationship. For instance, in the example 'The solutions were simple, tangible and local', 'the solutions' (part 1) are characterised as displaying the qualities of 'simple, tangible and local' (part 2). In this example the verb 'were' represents the strategy characterizing, a relatively weak form of epistemological condensation (EC-) because there is a one-way transfer of meaning in that only 'the solutions' has acquired additional meaning.

As a text unfolds, knowledge is built by progressively relating more and more meanings with each other. At first, an idea, concept, term, or piece of knowledge may relate out to only a small set of meanings. But through the text, it may gather more and more meanings and become more and more complex. The clausing tool allows us to see how this is done. For example, in the following sentence, 'The solutions proposed by the participants are linked to right-wing understandings of climate change which are biased', the concept of the 'the solutions' is progressively condensed in three ways: first, it is associated to the participants through 'proposed by the participants'; second, it is linked to the notion of 'right-wing understandings of climate change'; and third, it is characterised as being 'biased'. To assist in making the connections (and thus condensation) more explicit, tables are used in the analysis to demonstrate how meanings get condensed as they are carried forward. Furthermore, a simple diagrammatic method is also presented as an additional way to reveal effects of condensation of meaning, particularly when comparing texts. These two methods will be explained in detail as the analysis unfolds.

\section{Analysis: Revealing how complexity of meaning is built}

The following section provides an analysis of two texts. The first is a draft version of a data chapter from an Australian social science doctoral dissertation. The second text is taken from the same candidate's final, successfully examined dissertation. The comparison of the two texts enables one to see how the craft of theorising develops over time - in this instance, demonstrated through the candidate's ability to build complexity of meaning. In the two texts the candidate is describing and discussing a focus groups perceptions of climate change in terms of its 'problems' and potential 'solutions'. To construct a more theoretical and complex understanding of the data, the candidate is applying theoretical concepts from $\mathrm{LCT}^{3}$ - an explicit sociological theory, deriving from Bourdieu and Bernstein. The framework provides explicit theoretical concepts (e.g. 'epistemic relations') as well as theoretical codings (e.g. 'ER+') which are used to interpret and code empirical data. It is therefore an example of a very explicit theoretical framework. Both texts include rich empirical description and theory; however, the final version is considered more successful than the draft. The following analysis helps unpack why this is the case.

\footnotetext{
${ }^{3}$ Given that the texts analysed in this paper also happen to use LCT, all examples extracted from the texts are presented in quotation marks to avoid possible confusion.
} 


\section{Draft text}

In the first extract, taken from the draft text, the candidate incorporates theoretical terms (e.g. 'semantic gravity, SG+', 'semantic density, SD-', and '(SG+, SD-)') to help interpret her participants' understanding of climate change and how it affects them.

\section{Extract 1: Draft text}

Whereas the carbon tax works indirectly to reduce emissions, a complex mechanism that is invisible to lay people except through the negative experience of paying higher electricity bills, the solutions supported by participants were simple, tangible, local solutions - in LCT terms the solutions exhibit strong semantic gravity, $S G+$, and weak semantic density, $S D$-. As George said in the interview: it was "a very money-focussed conversation" - material, tangible, personal/selfish in terms of "how does it affect me?' Ditto all the conversations about waste, littering, landfills - material, tangible. Prioritise action on other issues such as starvation and plastic rubbish floating in the ocean: both material - in contrast to climate change - indirect and can only be observed by climate scientists. Similarly, as pointed out by Ted the recovery of the ozone layer is not directly perceptible by lay people. The types of actions that participants identified for "do the right thing", (recycle, compost, don't litter, pick up others' litter, turn off the lights, plant trees, keep the backyard mown and tidy, get smoky car emissions fixed at the mechanic) are all very local, tangible, specific solutions (SG+, SD-).

Despite drawing on theoretical concepts, the candidate essentially provides a largely descriptive account of how the participants understood climate change. Although she does include a few theoretical concepts, this is done with limited integration. Due to the detailed nature of the clausing tool the analysis will focus on the following short excerpt from the draft text. The verbs ${ }^{4}$ establishing the clausing relationships are underlined:

Similarly, as pointed out by Ted the recovery of the ozone layer is not directly perceptible by lay people. The types of actions that participants identified for "do the right thing", (recycle, compost, don't litter, pick up others' litter, turn off the lights, plant trees, keep the backyard mown and tidy, get smoky car emissions fixed at the mechanic) are all very local, tangible, specific solutions $(S G+, S D-)$

Tables 2 - 4 reveal the different strategies which act to condense meanings over time. In the first instance (Table 2), 'the recovery of the ozone layer' is related to 'Ted' through a characterizing strategy:

\footnotetext{
${ }^{4}$ As can be seen in the excerpt of text, at times the clausing relationship can be established by a bracket which links two short passages together. In doing so, the bracket acts to identify the two parts together through a relation of 'is' (technically, in linguistics, this technique is known as apposition).
} 
Table 2: Deconstruction of draft text, passage 1 - 2

\begin{tabular}{|l|l|l|l|c|}
\hline & \multicolumn{1}{|c|}{ SHORT PASSAGE } & \multicolumn{1}{|c|}{ PART 1 } & \multicolumn{1}{|c|}{ PART 2 } & $\begin{array}{c}\text { RELATION TYPE \& } \\
\text { STRENGTH }\end{array}$ \\
\hline $\mathbf{1}$ & $\begin{array}{l}\text { Similarly, as pointed out by Ted the } \\
\text { recovery of the ozone layer }\end{array}$ & $\begin{array}{l}\text { the recovery of } \\
\text { the ozone layer }\end{array}$ & Ted & $\begin{array}{c}\text { EC }-^{5} \\
\text { (characterizing) }\end{array}$ \\
\hline $\mathbf{2}$ & $\begin{array}{l}\text { Similarly, as pointed out by Ted the } \\
\text { recovery of the ozone layer is not } \\
\text { directly perceptible by lay people. }\end{array}$ & $\begin{array}{l}\text { the recovery of } \\
\text { the ozone layer }\end{array}$ & $\begin{array}{l}\text { directly } \\
\text { perceptible by } \\
\text { lied }\end{array}$ & $\begin{array}{l}\text { EC }- \\
\text { lcharacterizing) }\end{array}$ \\
\hline
\end{tabular}

The characterizing strategy adds meaning by dramatizing part 1 with part 2 through the addition of an action. Once this relation has been established, it is then carried forward in the second part of the passage (indicated in square brackets in 'part 1'). This condensed meaning ('the recovery of the ozone layer which has been pointed out by Ted') is then related to more meanings ('not directly perceptible by lay people') in the second instance. It is now evident that 'the recovery of the ozone layer' has taken on the additional meanings of 'pointed out by Ted' and 'not directly perceptible by lay people'.

This process of condensation can be diagrammed in a simple representation using a series of blocks to represent the different parts of meaning which are connected through a strategy. The type of strategy used is represented by one of four lines: a single line represents the weakest level of condensation, establishing, double lines represents the strategy of characterising, triple lines represents the coordinating strategy and four lines represents taxonomizing, the strongest level of condensation. An example of each is provided in Figure 1.

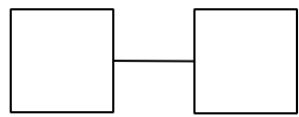

establishing (EC--)

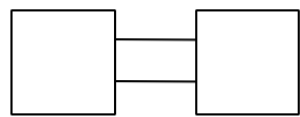

characterising (EC-)

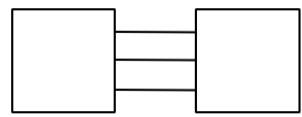

coordinating $(\mathrm{EC}+)$

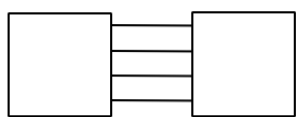

taxonomising $(\mathrm{EC}++)$

Figure 1: Representation of clausing strategies

When condensed meanings are carried forward into further clausing relationships, the condensed ('packed up') meanings are represented by an outer rectangle that shows what meaning has been carried forward, for example in Figure 2.

\footnotetext{
${ }^{5}$ Again, the (-) symbol here signifies the fact that relatively few additional meanings are being added through the specific relation, not that there is a loss of meaning.
} 


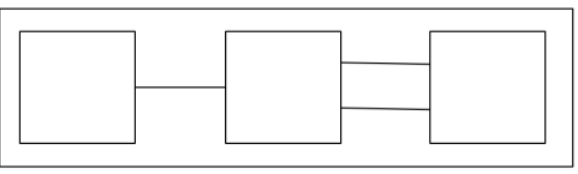

Figure 2: Representation of condensed meanings carried forward

Following the above criteria, the analysis presented in Table 2 can thus be represented as the following in Figure 3:

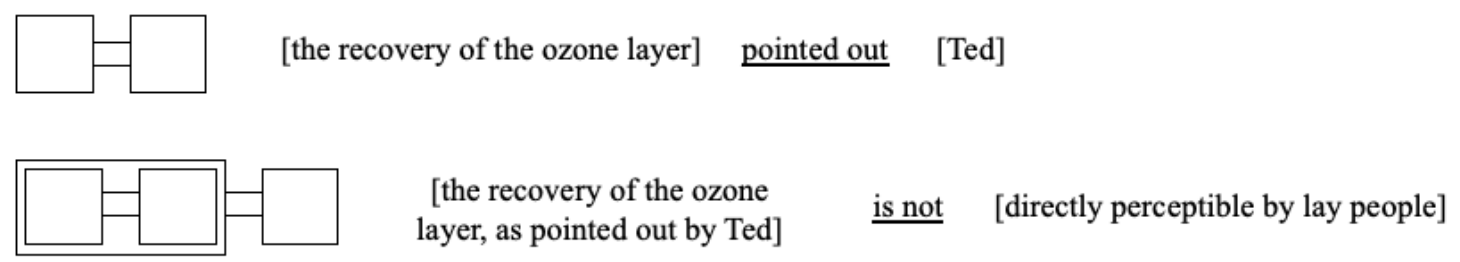

Figure 3: Representation of Table 2

The candidate then turns to a new idea, creating a break in the text. Rather than carrying forward established meanings, the candidate introduces new meanings. This process is unpacked in Table 3.

Table 3: Deconstruction of draft text, passage 3 - 4

\begin{tabular}{|c|c|c|c|c|}
\hline & SHORT PASSAGE & PART 1 & PART 2 & $\begin{array}{l}\text { RELATION } \\
\text { TYPE \& } \\
\text { STRENGTH }\end{array}$ \\
\hline 1 & $\begin{array}{l}\text { The types of actions for "do the } \\
\text { right thing", that participants } \\
\text { identified }\end{array}$ & $\begin{array}{l}\text { types of actions } \\
\text { for "do the right } \\
\text { thing" }\end{array}$ & participants & $\begin{array}{c}\mathrm{EC}- \\
\text { (characterizing) }\end{array}$ \\
\hline 2 & $\begin{array}{l}\text { The types of actions that } \\
\text { participants identified for "do the } \\
\text { right thing", (recycle, compost, } \\
\text { don't litter, pick up others' litter, } \\
\text { turn off the lights, plant trees, keep } \\
\text { the backyard mown and tidy, get } \\
\text { smoky car emissions fixed at the } \\
\text { mechanic) }\end{array}$ & $\begin{array}{l}\text { types of actions } \\
\text { for "do the right } \\
\text { thing" } \\
\text { [participants] }\end{array}$ & $\begin{array}{l}\text { recycle, compost, } \\
\text { don't litter, pick up } \\
\text { others' litter, turn off } \\
\text { the lights, plant trees, } \\
\text { keep the backyard } \\
\text { mown and tidy, get } \\
\text { smoky car emissions } \\
\text { fixed at the mechanic }\end{array}$ & $\begin{array}{c}\mathrm{EC}++ \\
\text { (taxonomizing) }\end{array}$ \\
\hline
\end{tabular}

As can be seen in Table 3, the candidate adds a dramatizing quality to part 1 through the use of a characterizing strategy. As such, 'types of actions for "do the right thing"' is linked to 'identified by the participants'. Next, the candidate condenses more meanings at a quicker rate when the now condensed meaning of "the types of actions for "do the right thing" as identified by the participants' is broken up into a series of types of actions ('recycle, compost, don't litter, 
pick up others' litter, turn off the lights, plant trees, keep the backyard mown and tidy, get smoky car emissions fixed at the mechanic') through the strategy of taxonomizing. This process is illustrated in Figure 4.
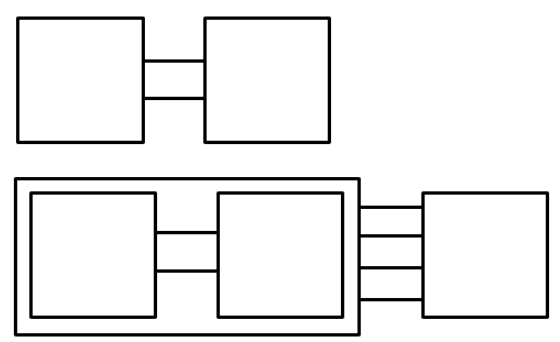

Figure 4: Representation of Table 3

The candidate then 'packs up' these already condensed meanings and adds further meaning by characterizing them with the quality of being 'very local, tangible, specific solutions', evident in Table 4, line 1.

Table 4: Deconstruction of draft text, passage 5 - 6

\begin{tabular}{|c|c|c|c|c|}
\hline & SHORT PASSAGE & PART 1 & PART 2 & $\begin{array}{l}\text { RELATION } \\
\text { TYPE \& } \\
\text { STRENGTH }\end{array}$ \\
\hline 1 & $\begin{array}{l}\text { The types of actions that } \\
\text { participants identified for "do } \\
\text { the right thing", (recycle, } \\
\text { compost, don't litter, pick up } \\
\text { others' litter, turn off the lights, } \\
\text { plant trees, keep the backyard } \\
\text { mown and tidy, get smoky car } \\
\text { emissions fixed at the } \\
\text { mechanic) are all very local, } \\
\text { tangible, specific solutions }\end{array}$ & $\begin{array}{l}\text { types of actions for "do the } \\
\text { right thing" } \\
\text { [participants] } \\
\text { [recycle, compost, don't } \\
\text { litter, pick up others' litter, } \\
\text { turn off the lights, plant } \\
\text { trees, keep the backyard } \\
\text { mown and tidy, get smoky } \\
\text { car emissions fixed at the } \\
\text { mechanic] }\end{array}$ & $\begin{array}{l}\text { very local, } \\
\text { tangible, } \\
\text { specific } \\
\text { solutions }\end{array}$ & $\begin{array}{c}\mathrm{EC}- \\
\text { (characterizing) }\end{array}$ \\
\hline 2 & $\begin{array}{l}\text { The types of actions that } \\
\text { participants identified for "do } \\
\text { the right thing", (recycle, } \\
\text { compost, don't litter, pick up } \\
\text { others' litter, turn off the lights, } \\
\text { plant trees, keep the backyard } \\
\text { mown and tidy, get smoky car } \\
\text { emissions fixed at the } \\
\text { mechanic) are all very local, } \\
\text { tangible, specific solutions } \\
\text { (SG+, SD-) }\end{array}$ & $\begin{array}{l}\text { types of actions for "do the } \\
\text { right thing" } \\
\text { [participants] } \\
\text { [recycle, compost, don't } \\
\text { litter, pick up others' litter, } \\
\text { turn off the lights, plant } \\
\text { trees, keep the backyard } \\
\text { mown and tidy, get smoky } \\
\text { car emissions fixed at the } \\
\text { mechanic] } \\
\text { [very local, tangible, specific } \\
\text { solutions] }\end{array}$ & $(\mathrm{SG}+, \mathrm{SD}-)$ & $\begin{array}{c}\mathrm{EC}++ \\
\text { (taxonomizing) }\end{array}$ \\
\hline
\end{tabular}


The strength of condensation changes in the next move (line 2, Table 4) however, when the strategy of taxonomizing is used to establish a type-type classificatory relation, resulting in increased amounts of condensation. Here, the already condensed meaning ('The types of actions that participants identified for "do the right thing", (recycle, compost, don't litter, pick up others' litter, turn off the lights, plant trees, keep the backyard mown and tidy, get smoky car emissions fixed at the mechanic) are all very local, tangible, specific solutions') is related to the theoretical coding '(SG+; SD-)'. The clausing relationship is set up by the bracket, which acts to connect the two passages through the relation of ' $i s$ '. In effect, the multiple meanings that have been packed into part 1 can then be classified as sharing the same meaning as that of part 2. Using the theoretical coding '(SG+; SD-)' further amplifies the rate of condensation, as this concept is a technical term that carries specialist meaning from a theoretical domain of LCT. The process of condensation occurring in Table 4 is diagrammed in Figure 5.

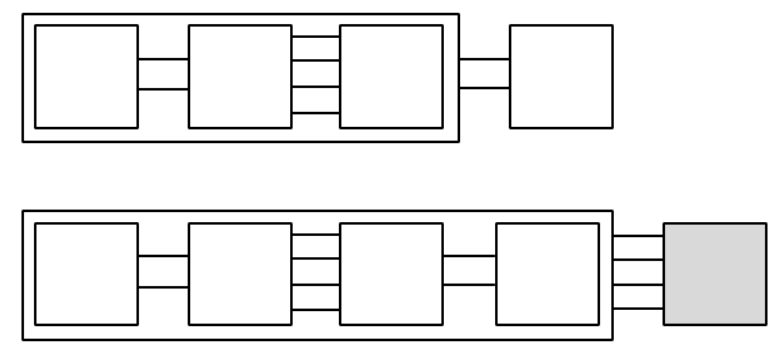

Figure 5: Representation of Table 4

Note in Figure 5, the use of shading for representing the theoretical meaning '(SG+; SD-)'. The shading represents a theoretical concept's 'technical' meaning, which is embedded in the term due to its 'location within a specialised domain of practice' (Maton and Doran, 2017a: 58). This means that the term already holds complex meaning due to the fact that it is part of a complex set of ideas that forms a specific theory. As such, when a technical term is used within a text, the condensation gets amplified (i.e. the theoretical concept creates an additional layer of condensation on top of the clausing strategy being enacted). This additional condensation is therefore represented with shading in the diagram.

When visualizing the effects of the culmination of clausing strategies used in the text in diagram form (see Figure 6), we can see how meanings are condensed in different ways and at different strengths. Each line of blocks in Figure 6 corresponds to a line of analysis, as presented in Tables 2 - 4 above. 

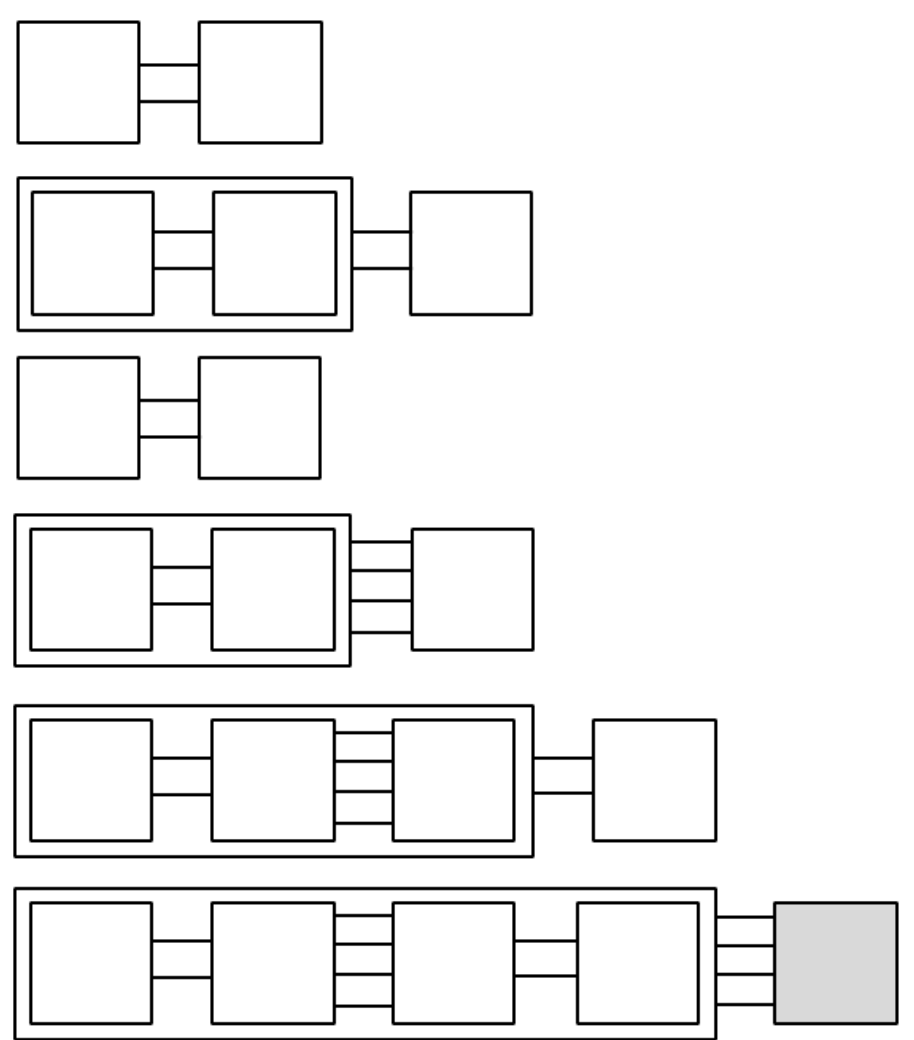

Figure 6: Overall effect of condensation in the draft text

Given that condensation is achieved in this extract using mostly relatively weaker condensation strategies - i.e. characterizing (visualised with double-lines linking the boxes) - the meaning builds relatively slowly. Figure 6 also shows how the text is 'disrupted' (see line 3), when new ideas are introduced (i.e. when established meanings are no longer carried forward). This 'disruption' limits the consolidation of meanings, preventing stronger levels of condensation. It is also evident how theoretical meaning is incorporated using the strongest clausing strategy (taxonomizing) right at the end of the extract. This indicates a marked jump to complexity in the final passage, creating a disjointed feel to the text - as though a theoretical coding has been 'tagged' onto the data rather than fully worked through and integrated.

\section{Final text}

In contrast to the more descriptive nature of the draft text, the final text engages with theory in a more sophisticated manner. In the following extract, the candidate is summing up the description that has come before and is now turning to theory to make sense of the data in more generalised terms, adding complexity as she goes. 
Extract 2: Final text

As a general pattern, the solutions that the Rotary participants said they supported aligned with their knower code and prosaic code while those that they opposed did not. Carbon pricing ("the carbon tax") provides a clear example of how the dimensions of Specialization and Semantics worked against its acceptance by participants. In the form in which it was developed, carbon pricing was based on technical assessments of pollutant emissions, modelling, verification and compliance, all of which exhibit stronger epistemic relations (ER+). The social elements relating to consumers' or industry tastes and preferences or motivations for action do not feature strongly, reflecting weaker social relations (SR-): a knowledge code (ER+, SR-). Further, carbon pricing is an abstract, intangible solution that thereby exhibits weaker semantic gravity ( $S G-$ ) and it is highly complex involving indirect chains of causation and effect, reflecting stronger semantic density $(S D+)$ : a rhizomatic code $(S G-, S D+)$.

Just like the draft, the candidate uses theory (seen in terms 'Specialization', 'epistemic relations (ER+)', social relations (SR-)', 'knowledge code (ER+, SR-)', semantic gravity (SG-)', 'semantic density (SD+)', and 'rhizomatic code (SG-; $S D+)$ ') to code and make sense of her data. The difference, however, is that these concepts are now more integrated with the description, enabling the text to appear to have a more direct and confident logic underpinning it. From an initial reading it is clear that it is not a case of one text using theory and one not - what separates these two texts is how the theory is used and incorporated. The following analysis helps makes this difference clearer. Once again, only a short excerpt is used given the detailed nature of the tool. The verbs creating the clausing connections are underlined:

Further, carbon pricing is an abstract, intangible solution that thereby exhibits weaker semantic gravity_(SG-) and it is highly complex involving indirect chains of causation and effect, reflecting stronger semantic density $(S D+)$ : a rhizomatic code_(SG-, $S D+$ ).

This short excerpt acts to condense meanings into the concept of 'carbon pricing'. The candidate manages to condense multiple meanings at a relatively quick pace through the use of key clausing strategies that progressively incorporate theoretical complexity. Outlined in Table 5 (line 1), 'carbon pricing' (part 1) is imbued with the properties of 'an abstract, intangible solution' (part 2) through the relatively weaker condensation strategy of characterising. Next, the candidate connects the additional quality of 'weaker semantic gravity' to the already condensed 'carbon pricing, which is an abstract, intangible solution'. At this stage, the (technical) theoretical concept of 'semantic gravity' is added as an additional property which creates relatively weaker condensation of meaning (despite it being a theoretical term). 
Table 5: Deconstruction of final text, passage 1 - 3

\begin{tabular}{|c|c|c|c|c|}
\hline & SHORT PASSAGE & PART 1 & PART 2 & $\begin{array}{l}\text { RELATION TYPE } \\
\text { \& STRENGTH }\end{array}$ \\
\hline 1 & $\begin{array}{l}\text { Further, carbon pricing is an abstract, } \\
\text { intangible solution }\end{array}$ & carbon pricing & $\begin{array}{l}\text { an abstract, } \\
\text { intangible } \\
\text { solution }\end{array}$ & $\begin{array}{c}\mathrm{EC}- \\
\text { (characterizing) }\end{array}$ \\
\hline 2 & $\begin{array}{l}\text { Further, carbon pricing is an abstract, } \\
\text { intangible solution that thereby } \\
\text { exhibits weaker semantic gravity }\end{array}$ & $\begin{array}{l}\text { carbon pricing } \\
\text { [an abstract, } \\
\text { intangible } \\
\text { solution] }\end{array}$ & $\begin{array}{l}\text { weaker } \\
\text { semantic } \\
\text { gravity }\end{array}$ & $\begin{array}{c}\mathrm{EC}- \\
\text { (characterizing) }\end{array}$ \\
\hline 3 & $\begin{array}{l}\text { Further, carbon pricing is an abstract, } \\
\text { intangible solution that thereby } \\
\text { exhibits weaker semantic gravity_SG-) }\end{array}$ & $\begin{array}{l}\text { carbon pricing } \\
\text { [an abstract, } \\
\text { intangible } \\
\text { solution] } \\
\text { [weaker } \\
\text { semantic } \\
\text { gravity] }\end{array}$ & $(\mathrm{SG}-)$ & $\begin{array}{c}\text { EC }++ \\
\text { (taxonomizing) }\end{array}$ \\
\hline
\end{tabular}

Following this, the candidate then applies a theoretical coding ('SG-') to the interpretation (line 3, Table 5). In doing so, all the meanings in part 1 in line 3 get packed up and classified as a type-type relation to the meaning in part 2 ('SG-'). The taxonomizing strategy condenses many meanings very quickly because it connects the condensed meanings associated with 'carbon pricing' in part 1 to the specialised domain of the theory being used (represented by '(SG-)') in part 2. This process of condensation is graphically represented in Figure 7.
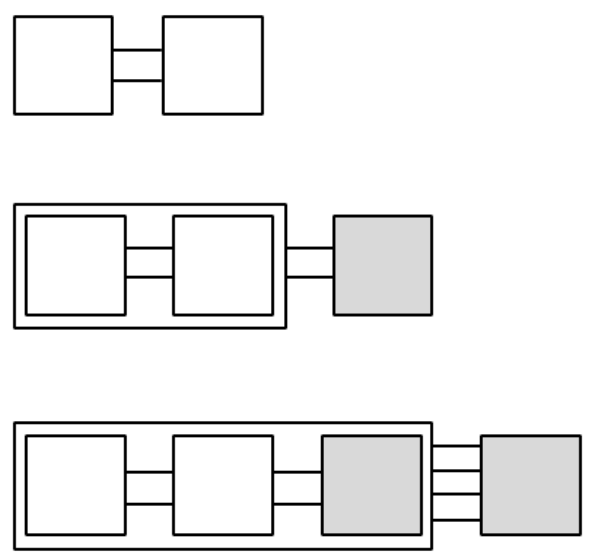

Figure 7: Representation of Table 5

As the text unfolds, the candidate repeats this process again, adding new meanings to 'carbon pricing' by adding more theoretical concepts and codings. As seen in Table 6 (line 1), 'carbon pricing', which has now taken on the additional meanings of 'an abstract, intangible 
solution that thereby exhibits weaker semantic gravity (SG-)', has the additional quality of being 'highly complex' added to it through the clausing relation of characterizing.

Table 6: Deconstruction of final text, passage 4 - 5

\begin{tabular}{|c|c|c|c|c|}
\hline & SHORT PASSAGE & PART 1 & PART 2 & $\begin{array}{l}\text { RELATION } \\
\text { TYPE \& } \\
\text { STRENGTH }\end{array}$ \\
\hline 1 & $\begin{array}{l}\text { Further, carbon pricing is an } \\
\text { abstract, intangible solution that } \\
\text { thereby exhibits weaker semantic } \\
\text { gravity (SG-) and it is highly } \\
\text { complex involving indirect chains } \\
\text { of causation and effect }\end{array}$ & $\begin{array}{l}\text { carbon pricing } \\
\text { [an abstract, intangible } \\
\text { solution] } \\
\text { [weaker semantic gravity] } \\
{[(S G-)]}\end{array}$ & $\begin{array}{l}\text { highly } \\
\text { complex }\end{array}$ & $\begin{array}{c}\mathrm{EC}- \\
\text { (characterizing) }\end{array}$ \\
\hline 2 & $\begin{array}{l}\text { Further, carbon pricing is an } \\
\text { abstract, intangible solution that } \\
\text { thereby exhibits weaker semantic } \\
\text { gravity (SG-) and it is highly } \\
\text { complex involving indirect chains } \\
\text { of causation and effect }\end{array}$ & $\begin{array}{l}\text { carbon pricing } \\
\text { [an abstract, intangible } \\
\text { solution] } \\
\text { [weaker semantic gravity] } \\
{[(S G-)]} \\
\text { [highly complex] }\end{array}$ & $\begin{array}{l}\text { indirect } \\
\text { chains of } \\
\text { causation } \\
\text { and effect }\end{array}$ & $\begin{array}{c}\mathrm{EC}+ \\
\text { (coordinating) }\end{array}$ \\
\hline
\end{tabular}

The candidate then adds more condensation of meaning using a coordinating clausing strategy that connects terms in contingent relations of correlation - i.e. the condensed meanings in part 1 are correlated with the meaning of 'indirect chains of causation and effect' in part 2 . This process of condensation is summarised in Figure 8.

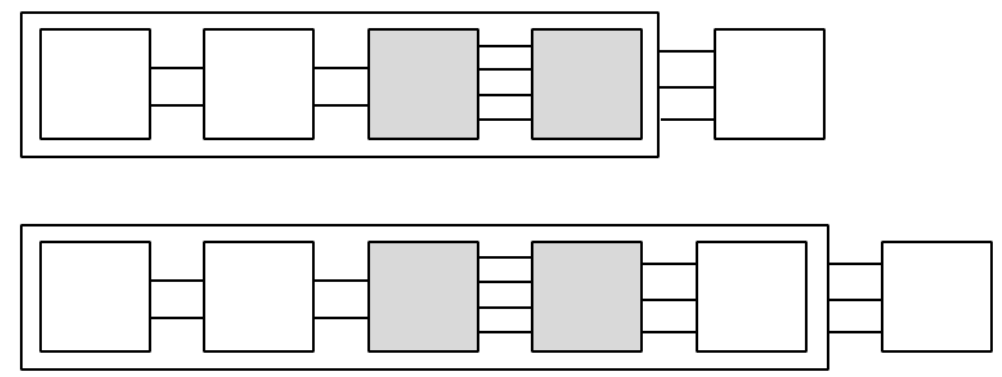

Figure 8: Representation of Table 6

Next, the candidate introduces more theoretical concepts (see Table 7). As done previously, the candidate first adds theoretical meaning by using a characterizing strategy, adding the properties of 'stronger semantic density' to the condensed meanings in part 1 . While the theoretical concept adds condensation in itself (in that it is already a technical term), the characterizing clausing relation builds meaning more gradually. 
Table 7: Deconstruction of final text, passage $6-7$

\begin{tabular}{|c|c|c|c|c|}
\hline & SHORT PASSAGE & PART 1 & PART 2 & $\begin{array}{l}\text { RELATION } \\
\text { TYPE \& } \\
\text { STRENGTH }\end{array}$ \\
\hline 1 & $\begin{array}{l}\text { Further, carbon pricing is an } \\
\text { abstract, intangible solution that } \\
\text { thereby exhibits weaker semantic } \\
\text { gravity (SG-) and it is highly } \\
\text { complex involving indirect chains } \\
\text { of causation and effect reflecting } \\
\text { stronger semantic density }\end{array}$ & $\begin{array}{l}\text { carbon pricing } \\
\text { [an abstract, intangible } \\
\text { solution] } \\
\text { [weaker semantic gravity] } \\
{[(S G-)]} \\
\text { [highly complex] } \\
\text { [indirect chains of causation } \\
\text { and effect] }\end{array}$ & $\begin{array}{l}\text { stronger } \\
\text { semantic } \\
\text { density }\end{array}$ & $\begin{array}{c}\mathrm{EC}- \\
\text { (characterizing) }\end{array}$ \\
\hline 2 & $\begin{array}{l}\text { Further, carbon pricing is an } \\
\text { abstract, intangible solution that } \\
\text { thereby exhibits weaker semantic } \\
\text { gravity (SG-) and it is highly } \\
\text { complex involving indirect chains } \\
\text { of causation and effect reflecting } \\
\text { stronger semantic density (SD+): }\end{array}$ & $\begin{array}{l}\text { carbon pricing } \\
\text { [an abstract, intangible } \\
\text { solution] } \\
\text { [weaker semantic gravity] } \\
\text { [(SG-)] } \\
\text { [highly complex] } \\
\text { [indirect chains of causation } \\
\text { and effect] } \\
\text { [stronger semantic density] }\end{array}$ & $(\mathrm{SD}+)$ & $\begin{array}{c}\mathrm{EC}++ \\
\text { (taxonomizing) }\end{array}$ \\
\hline
\end{tabular}

The candidate then applies a theoretical coding ('(SD+)') using taxonomizing (Table 7, line 2). This strategy creates a classificatory relation of type-type in that it packs up all the meanings in part 1 to share the same meaning as part 2, as evident in the Figure 9.

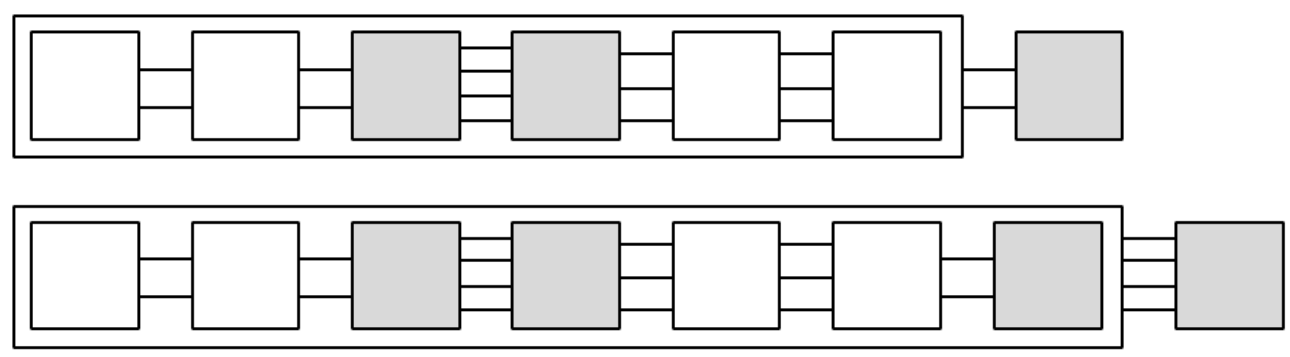

Figure 9: Representation of Table 7

Finally, the candidate sums up all the condensed meanings presented so far in the text through a theoretical interpretation ('a rhizomatic code') and then through a theoretical coding ('(SG-, SD+)'), as can be seen in Table 8. Here, taxonomizing does not add more properties to the term (which would be done through characterizing); instead, the candidate uses it to pack all prior meanings into a highly synthesised and condensed theoretical interpretation. The candidate repeats this strategy when assigning a further theoretical coding to the interpretation. 
Table 8: Deconstruction of final text, passage 8 - 9

\begin{tabular}{|c|c|c|c|c|}
\hline & SHORT PASSAGE & PART 1 & PART 2 & $\begin{array}{l}\text { RELATION } \\
\text { TYPE \& } \\
\text { STRENGTH }\end{array}$ \\
\hline 1 & $\begin{array}{l}\text { Further, carbon pricing is an } \\
\text { abstract, intangible solution } \\
\text { that thereby exhibits weaker } \\
\text { semantic gravity (SG-) and it } \\
\text { is highly complex involving } \\
\text { indirect chains of causation } \\
\text { and effect reflecting stronger } \\
\text { semantic density (SD+): a } \\
\text { rhizomatic code }\end{array}$ & $\begin{array}{l}\text { carbon pricing } \\
\text { [an abstract, intangible solution] } \\
\text { [weaker semantic gravity] } \\
\text { [(SG-)] } \\
\text { [highly complex] } \\
\text { [indirect chains of causation and } \\
\text { effect] } \\
\text { [stronger semantic density] } \\
{[(S D+)]}\end{array}$ & $\begin{array}{l}\text { a rhizomatic } \\
\text { code }\end{array}$ & $\begin{array}{c}\mathrm{EC}++ \\
\text { (taxonomizing) }\end{array}$ \\
\hline 2 & $\begin{array}{l}\text { Further, carbon pricing is an } \\
\text { abstract, intangible solution } \\
\text { that thereby exhibits weaker } \\
\text { semantic gravity (SG-) and it } \\
\text { is highly complex involving } \\
\text { indirect chains of causation } \\
\text { and effect reflecting stronger } \\
\text { semantic density (SD+): a } \\
\text { rhizomatic code_(SG-, SD+). }\end{array}$ & $\begin{array}{l}\text { carbon pricing } \\
\text { [an abstract, intangible solution] } \\
\text { [weaker semantic gravity] } \\
\text { [(SG-)] } \\
\text { [highly complex] } \\
\text { [indirect chains of causation and } \\
\text { effect] } \\
\text { [stronger semantic density] } \\
\text { [(SD+)] } \\
\text { [a rhizomatic code] }\end{array}$ & $(\mathrm{SG}-, \mathrm{SD}+)$ & $\begin{array}{c}\mathrm{EC}++ \\
\text { (taxonomizing) }\end{array}$ \\
\hline
\end{tabular}

When the final text is illustrated in a diagram, the following condensation structure is revealed (see Figure 10).

Figure 10 reveals how the final text adopts a cumulative structure that progressively builds knowledge piece by piece. This is achieved by enacting a nuanced selection of clausing strategies that move back and forth between weaker and stronger condensation. Crucially, the choice of strategies ensures that all meanings that are presented are related to prior meanings and packed up into a whole. This is done through a general pattern that begins with relatively weak condensation strategies, before gradually introducing theoretical concepts and relating them to the meanings already developed in the text. Finally, through taxonomizing these meanings are then consolidated into a complex theoretical interpretation. This pattern of integrating theory through weaker to stronger clausing strategies creates a gradual yet definite increase in complexity of meaning. 

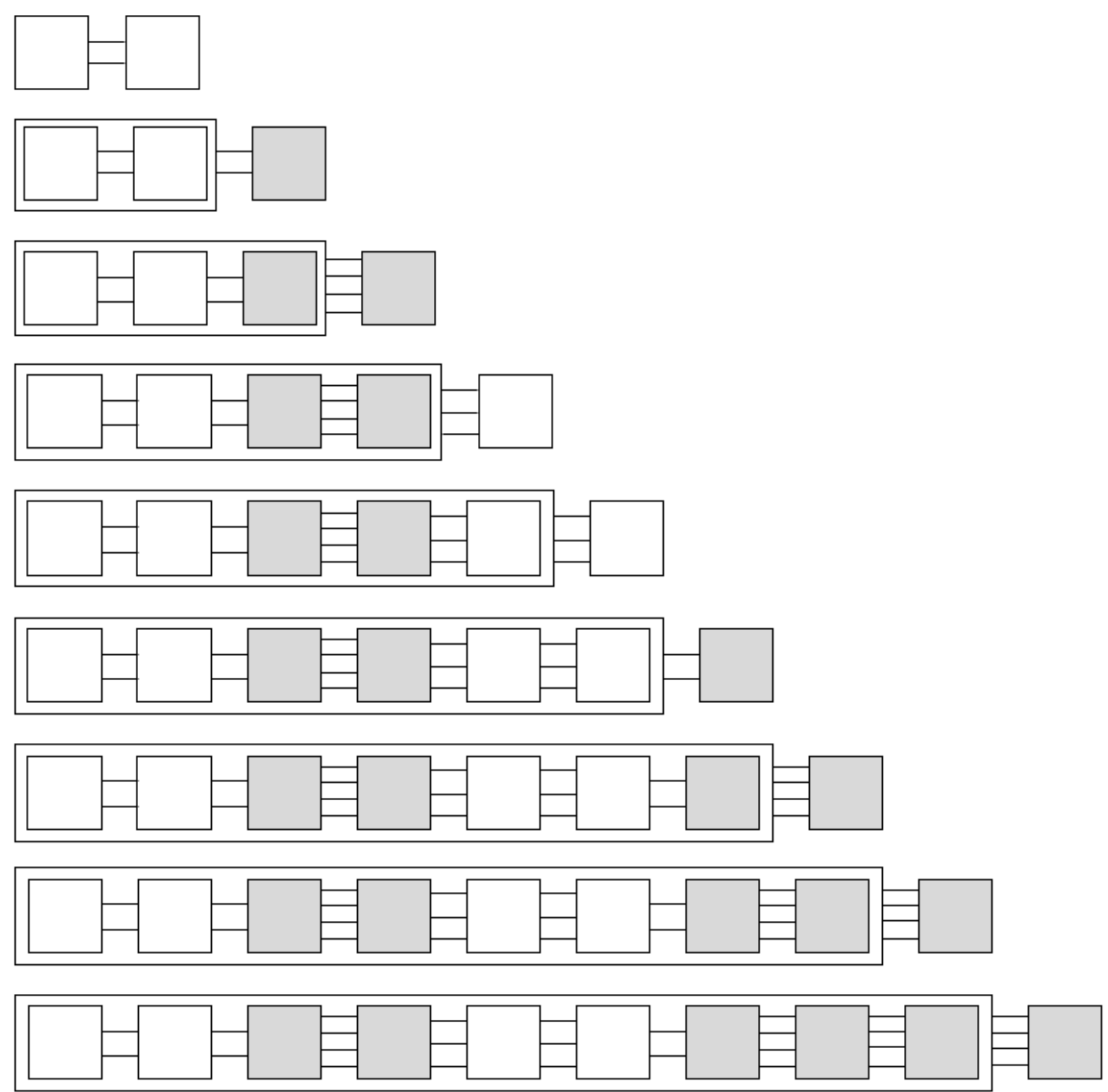

Figure 10: Overall effect of condensation in the final text

\section{The value of making knowledge explicit}

The analysis presented above shows how the use of a conceptual tool that is capable of revealing knowledge-building strategies is able to show what successful theorising looks like in this case. In particular, the tool reveals how the pattern of knowledge-building in the final text is different to the candidate's draft version: the draft text is shown to build complexity more slowly, through mostly characterising strategies, and then jumps to theory at the end by moving straight from characterising to taxonomizing strategies. This jump creates a disjointed feel to the text, as though theory has been 'tagged on' rather than working through description, explanation and theoretical interpretation, as the candidate does in the final text. In the final text, the analysis reveals a more gradual movement of working incrementally through the different strategies as complexity is built up over time. In this case, successful theorising involves using relatively weak condensation strategies that first characterises empirical data with theoretical meanings (through characterising), before creating stronger relations of causation and/or correlation between empirical data and theoretical concepts (through coordinating), and then finally coding the interpretations by classifying the meanings created within a theoretical schema (through 
taxonomizing).

The particular pattern of strategies identified here as 'successful knowledge-building' relate to the specific theoretical framework used by the candidate. Being an explicit framework, the theoretical concepts are applied to data in particular, explicit ways. Not all theories will behave in the same way. As such, the findings of this paper are not intended to be a one-size-fits-all model or 'ideal' way to theorise for all doctoral candidates using any kind of theory - different theories will inevitably be enacted in a variety of nuanced ways in research. What this analysis does reveal, however, is the ability of the clausing tool to unpack a complicated and (often) obscure process that develops implicitly through the drafting process. As such, it offers crucial insight into how LCT was successfully integrated and operationalised in the candidate's dissertation - insight which can be taken up by those working with this particular theory. Importantly, however, it additionally opens the possibility of using this tool to analyse the enactment of a range of other theories in doctoral writing, so that insights can be generated for more supervisors/researchers working in the social sciences and beyond. In this way, this paper offers a kind of 'proof of concept' to show the value of using knowledge-focused tools to understand key aspects of doctoral writing that can be used to complement and enhance existing linguistic understandings.

A further caveat to note is that I am not suggesting that the clausing tool be used as a teaching tool in/for doctoral supervision in its current form. The strength of the clausing tool is its ability to conduct fine-grained analyses on small(er) pieces of text. While it is not impossible to use the tool for pedagogic purposes, it would be a lengthy and highly detailed process, which may overwhelm a candidate. Rather, the argument put forward is that a knowledge-focused tool, such as the one which has been demonstrated in this paper, can be used to unpack the opaque process of theorising in doctoral writing, which in turn, can enable a deeper understanding of how theory is used, and to what effect. In essence, the clausing tool from LCT is able to make tangible a process that is inherently known but seldom explained in concrete, practical terms. Gaining this more explicit understanding is argued to be a necessary first step for future pedagogic development.

\section{Acknowledgements}

Many thanks to Dr Eleanor Glenn for providing access to the draft versions of her thesis for this analysis. Thanks also go to Dr Yaegan Doran for being a critical reader on earlier drafts of this paper.

\section{Author Biography}

Kirstin Wilmot is the coordinator of the Higher Education Studies Doctoral Programme in the Centre for Higher Education Research, Teaching and Learning at Rhodes University. Her research focuses on developing theoretical tools for analysing and understanding disciplinary knowledgebuilding practices, with a particular interest in doctoral writing and postgraduate supervision. 


\section{References}

Clegg, S. 2012. On the Problem of Theorising: An Insider Account of Research Practice. Higher Education Research and Development, 31(3): 407-18.

Denicolo, P. 2016. International developments in the purpose and process of the doctorate: Consequences for supervision, examining and the employment of graduates. In FourieMalherbe, M., Albertyn, R., Aitchison, C., \& Bitzer, E. Postgraduate Supervision: Future foci for the knowledge society. Stellenbosch: SUN MeDIA, 15-32.

Glenn, E. 2015. Cooking with LCT. Sydney LCT Roundtable, University of Sydney, Australia.

Glenn, E. 2016. From Clashing to Matching: Examining the legitimation codes that underpin shifting views about climate change. Unpublished PhD diss., Institute for Sustainable Futures, University of Technology Sydney, Australia.

Holbrook, A., Bourke, S. \& Fairbairn, H. 2015. Examiner reference to theory in PhD theses. Innovations in Education and Teaching International, 52(1): 75-85.

Jackson, A.Y., \& Mazzei, L.A. 2012. Thinking with theory in qualitative research: Viewing data across multiple perspectives. Abingdon: Routledge.

Kiley, M. \& Wisker, G. 2009. Threshold concepts in research education and evidence of threshold crossing. Higher Education Research \& Development, 28(4): 431-441.

Lovitts, B. 2007. Making the Implicit Explicit: Creating Performance Expectations for the Dissertation. Sterling, Virginia: Stylus Publishing.

Maton, K. \& Doran, Y. 2017a. Semantic density: A translation device for revealing complexity of knowledge practices in discourse, part 1 - wording. Onomazein, 46-76.

Maton, K. \& Doran, Y. 2017b. Condensation: A translation device for revealing complexity of knowledge practices in discourse, part 2 - clausing and sequencing. Onomazein, 77-110.

Maton, K. 2014. Knowledge and Knowers: Towards a Realist Sociology of Education. Abingdon: Routledge.

Mouton, J. 2016. The doctorate in South Africa: Trends, challenges and constraints. In FourieMalherbe, M., Albertyn, R., Aitchison, C., \& Bitzer, E. Postgraduate Supervision: Future Foci for the Knowledge Society. Stellenbosch: SUN MeDIA, 51-84.

Paltridge, B. 2002. Thesis and dissertation writing: An examination of published advice and actual practice. English for Specific Purposes, 21(2): 125-143.

Ravelli, L., Paltridge, B. \& Starfield, S. 2014. Diversity in creative and performing arts doctoral writing: A way forward. In Ravelli, L., Paltridge, B. \& Starfield, S. Doctoral writing in the creative and performing arts: The researcher/practitioner nexus. Faringdon: Libri, 389-406.

Starfield, S. \& Ravelli, L. 2006. 'The writing of this thesis was a process that I could not explore with the positivistic detachment of the classical sociologist': Self and structure in New Humanities research theses. Journal of English for Academic Purposes, 5(3): 222-243.

Swales, J. 1998. Textography: Toward a Contextualization of Written Academic Discourse. Research on Language and Social Interaction, 31(1): 109-121.

Trowler, P. 2016. Doctoral Research into Higher Education: Making theory work. Middletown, DE: CreateSpace Independent Publishing Platform. 
Wilmot, K. 2019. Enacting knowledge in dissertations: An exploratory analysis of doctoral writing using Legitimation Code Theory. Unpublished PhD diss., The University of Sydney, Australia. 